\title{
Switching from mesopredator to apex predator: how do responses vary in amphibians adapted to cave living?
}

\author{
Raoul Manenti $^{1}$ (D) $\cdot$ Andrea Melotto $^{1} \cdot$ Olivier Guillaume $^{2} \cdot$ Gentile Francesco Ficetola $^{1,3} \cdot$ Enrico Lunghi $^{4,5}$
}

Received: 1 July 2020 / Revised: 7 September 2020 / Accepted: 11 September 2020 / Published online: 21 September 2020

(C) The Author(s) 2020

\begin{abstract}
The effective detection of both prey and predators is pivotal for the survival of mesopredators. However, the condition of being a mesopredator is strongly context dependent. Here we focus on two aquatic caudate species that have colonised caves: the Pyrenean newt (Calotriton asper) and the olm (Proteus anguinus). The former maintains both surface and subterranean populations, while only cave-adapted populations of the latter exist. Both species are apex predators in underground waterbodies, while the Pyrenean newt is a mesopredator in surface waterbodies. Shifting to a higher level of the trophic web through colonising caves may promote the loss of anti-predator response against surface apex predators, and an increase in the ability to detect prey. To test these two non-exclusive hypotheses, we integrated classical behavioural characterisations with a novel approach: the assessment of lateralisation (i.e. preference for one body side exposure). Behavioural experiments were performed using laboratory-reared individuals. We performed 684 trials on 39 Pyrenean newts and eight olms. Under darkness and light conditions, we tested how exposure to different chemical cues (predatory fish, prey and unknown scent) affected individuals' activity and lateralisation. Both cave and surface Pyrenean newts responded to predator cues, while olms did not. In Pyrenean newts, predator cues reduced the time spent in movement and time spent in lateralisation associated with hunting. Our results show that predator recognition is maintained in a species where recently separated populations inhabit environments lacking of higher predators, while such behaviour tends to be lost in populations with longer history of adaptation.
\end{abstract}

\section{Significance statement}

Predator recognition can be maintained in animals adapted to predator free habitats, but varies with their history of adaptation. Species that are not at the apex of the food web can become top predators if they colonise subterranean environments. We compared the behavioural responses of the olm, a strictly cave species with a long underground evolutionary history, and of the Pyrenean newt, a facultative cave species that also has stream-dwelling populations. Moreover, we integrated a classical behavioural characterisation, such as movement detection, with a novel approach: the assessment of lateralisation. While olms do not respond to external predators scent, cave-dwelling newts still recognise it. This clearly indicates that predator recognition is still maintained in species that have colonised predator-free environments more recently.

Keywords Proteus $\cdot$ stream $\cdot$ seepage $\cdot$ newt $\cdot$ salamander $\cdot$ lateralisation

Communicated by A. Taylor Baugh

Electronic supplementary material The online version of this article (https://doi.org/10.1007/s00265-020-02909-x) contains supplementary material, which is available to authorized users.

Raoul Manenti

raoulmanenti@gmail.com

Andrea Melotto

mel8@hotmail.it

1 Department of Environmental Science and Policy, Universitòà degli studi di Milano, via Celoria, 26, 20133 Milan, Italy

2 Laboratoire Souterrain CNRS de Moulis, 2 Route du cnrs, 09200 Moulis, France
3 CNRS, Université Savoie Mont Blanc, LECA, Laboratoire d'Ecologie Alpine, Université Grenoble Alpes, F-38000 Grenoble, France

4 Key Laboratory of the Zoological Systematics and Evolution, Institute of Zoology, Chinese Academy of Sciences, Beichen West Road 1, Beijing 100101, China

5 Museo di Storia Naturale dell'Università degli Studi di Firenze, sede "La Specola", Via Romana 17,, 50125 Florence, Italia 


\section{Introduction}

Predator and prey recognition is a key behavioural aspect influencing the life history, evolution, and distribution of animals (Peckarsky et al. 2008). A number of studies have assessed behavioural responses during predator-prey interactions, often with strong emphasis on the importance of predator recognition (Brown and Godin 1999; Policht et al. 2019). The predator recognition continuum hypothesis (Ferrari et al. 2008) states that the ability of a prey to recognise predators strongly depends on both the spatial and temporal likelihood of being predated, and on the diversity of predators occurring locally. Under this scenario, innate predator recognition abilities are favoured in environments where the probability of being attacked by predators is high, but the diversity of predators is low (Ferrari and Chivers 2009; Haddaway et al. 2014; Diquelou and Griffin 2019). On the other hand, when the diversity of predators is high and the risk of being predated is not constant (e.g. because of seasonal variation of predator occurrence), the ability of learning how to recognise predators and modulating anti-predatory responses can be more advantageous than innate recognition (Ferrari et al. 2008).

Species holding different trophic positions face strongly differing constraints (Arim et al. 2007; Kishida et al. 2009; Manenti et al. 2015). For apex predators, the main challenges are represented by intraspecific competition and the effective detection of prey. However, animals occupying intermediate levels of food webs (mesopredators) hold the dual role of being both prey and predator (Haidir et al. 2018; Roos et al. 2018). Thus, mesopredators experience both the constraints of being potential prey, and of being predators needing effective prey recognition. Thus, understanding their behavioural modulation can greatly help unravel predator-prey interaction mechanisms. Even though being a meso- or an apex predator is generally related to body size, with larger predators preying upon smaller ones (Eklov and Svanback 2006; Donadio and Buskirk 2016), the position of a species within food webs is strongly context dependent and may differ between habitats and ontogenic stage (Ritchie and Johnson 2009; Braga et al. 2019). In streams without fish, dragonfly larvae are a classical example; at early life-stages, these organisms occupy an intermediate position in the food webs while, once they grow, they become the apex predators (Hopkins et al. 2011; Start 2018).

When compared with surface habitats, subterranean environments show strong differences in the abundance and diversity of both predators and trophic resources, with consequences for food web structure and the behaviour of animals (Culver and Pipan 2019). In caves, the availability of prey is reduced (Uiblein et al. 1992; Urban 2007). In turn, lack of trophic resources limits the number of predators; thus when an epigean mesopredator species is able to colonise subterranean environments, it may easily become an apex predator (Salvidio et al. 2017; Bradley and Eason 2018). A clear example is provided by the fire salamander Salamandra salamandra, an amphibian breeding in both surface streams and underground springs (Manenti et al. 2017). In surface streams, larvae are mesopredators, being predated by both fish and dragonfly (Manenti et al. 2009), while in caves, they are apex predators (Barzaghi et al. 2017). The behavioural consequences of shifting to a higher level in the food web remain poorly known. For instance, it is not known if the shift from meso to apex predator reduces the species' ability to recognise and avoid predator species, or increase prey detection ability through behavioural modification.

Underground environments can represent excellent natural laboratories in which to study such behavioural aspects, due to their greatly simplified trophic webs and reduced environmental fluctuations (Culver and Pipan 2019). Among European vertebrates, only one recently discovered fish (a loach of the genus Barbatula) and two amphibian caudates have stable populations in groundwater environments (Romero 2009; Behrmann-Godel et al. 2017), namely, the olm (Proteus anguinus) and the Pyrenean newt (Calotriton asper). The olm is a cave specialist that can survive and breed only in subterranean environments (Balazs et al. 2020), which it probably colonised approximately 8-20 Myr ago (Bulog 1994; Trontelj et al. 2007). Conversely, the Pyrenean newt has surface populations inhabiting headwaters, but also subterranean populations that have a certain degree of physiological and behavioural adaptation to cave life; these populations are believed to have only recently (after last glaciation) colonised subterranean environments (Hervant et al. 2000; Miaud and Guillaume 2005; Schlegel et al. 2009). Despite genetic differentiation which exists among populations from different areas of the Pyrenees, this process divergence is recent (beginning around the Last Glacial Maximum), and there is no clear distinction between surface and subterranean environments (Lucati et al. 2020). Both olms and Pyrenean newts are apex predators in their respective groundwater environments, while surface-dwelling Pyrenean newts are preyed upon by fish (Carranza and Amat 2005; Manenti et al. 2013a).

In this study, we tested two hypotheses related to the importance of predator and prey recognition in organisms shifting to a different trophic position. Predator detection decrease hypothesis: shifting to a higher level of the trophic web is expected to promote the loss of anti-predator responses to cues released by higher predators. We hypothesised that, while predator recognition is beneficial in populations inhabiting environments where higher predators are present, it may be reduced in populations exploiting safer environments, where higher predators are absent. Prey detection ability hypothesis: becoming apex predators in a resourcedepleted environment should favour the enhancement of prey detection ability. We hypothesised that in subterranean environments, characterised by low prey availability (JimenezValverde et al. 2017), active foraging behaviour is favoured 
by natural selection to increase prey detection, as observed in fire salamander larvae from cave-breeding populations (Manenti et al. 2013b). Here we performed behavioural tests to assess these hypotheses using the olm and the Pyrenean newt as model species, and measured their behavioural responses towards different chemical stimuli. An innovative method to measure stimuli detection and predator/prey recognition is to assess individuals' lateralisation. Recent studies showed that the left body side (connected to the right cerebral hemisphere) is generally linked to fast reactions towards predators, while the right body side (connected to the left brain hemisphere) is involved in predatory behaviours (Bonati et al. 2010, 2013; Schnell et al. 2016); yet, only few studies have assessed lateralisation in urodeles (Izvekov et al. 2018). We integrated the quantification of individuals' activity with the assessment of their lateralisation in response to different chemical cues. Movement measurement in a risky or foraging context is a classical approach to detect the effect of predators and trophic resources on behavioural patterns. A reduction in activity is an anti-predator response (Lima and Dill 1990; Bleicher 2017; Chin et al. 2018), while in the absence of stress or in presence of attractive stimuli (e.g. cues released by prey), individuals should spend more time in exploring the environment (Meager and Batty 2007; Hughes et al. 2010).Lateralised responses reflect the asymmetric processing of sensory inputs in the contralateral brain hemisphere, and are believed to improve composited motor activities such as recognising potential predators and in escaping (Fernandes et al. 2018). Detecting behavioural differences between populations can be challenging; thus, we used lateralised responses to better understand the relative role of predator and prey stimuli on our target species.

\section{Material and methods}

\section{Animals}

We performed our study using newts and olms reared in the Subterranean Laboratory of Moulis (Ariège, France). The study was performed in August 2016 and involved 39 adult newts (20 males and 19 females) and eight olms. Pyrenean newts belonging to five caves (20 individuals) and three streams (19 individuals) had been collected in 2007. The caves of origin are Cave of Labouich, Cave Bernard, Cave of Betharram, Cave of Pas du Loup and Cave of Vicdessos; the streams of origin are Ribaui, Cailla and Olhadoko. According to Lucati et al. (2020), the source populations of Pyrenean newts likely belong to two closely related lineages.

The eight olms were born in the Moulis cave laboratory between 1970 and 1976. The founder individuals of the breeding population of olms were collected in 1952 in the Piuka cave river near the town of Planina, Slovenia (Vandel and Bouillon 1954; Juberthie 1991).

Since their collection, Pyrenean newts and olms collected in caves have been reared and bred under darkness conditions, while newts from surface streams have been reared under a natural photoperiod using full spectrum daylight fluorescent lamps (True-light @Natural Daylight $5500 \mathrm{~K} /$ Colour Rendering $1 \mathrm{~A}, \mathrm{Ra}>90)$ during daytime $(12 / 12 \mathrm{~h}$ photoperiod). Pyrenean newts are reared in tanks of $80 \times 30 \times 20 \mathrm{~cm}$, while olms are in tanks of $500 \mathrm{~cm} 100 \times 100 \mathrm{~cm}$. Pyrenean newts are hosted depending on their population of origin with at least two tanks per population; in each tank, holed bricks are provided as shelters. For both stream and cave newts, the rearing temperature is constantly maintained at $12{ }^{\circ} \mathrm{C}$. All the individuals are fed with live Chironomus sp. and Artemia salina prey; feeding happens once a week and both newts and olms can prey ad libitum.

\section{Behavioural tests}

To assess the ability of surface- and cave-adapted urodeles to recognise potential predators and prey, we used related cues. The predator cue was obtained by collecting water from an aquarium of $80 \times 40 \times 40 \mathrm{~cm}$ in which two adult trout (Salmo trutta: one male and one female; size: $40 \mathrm{~cm}$ ) were maintained during the experiment. The aquarium was fed by a minimal continuous water flow, and we kept the two trout for $24 \mathrm{~h}$ without eating before collecting the water for the tests. Previous tests have demonstrated that aquatic urodeles are able to detect and respond to this kind of predator cue (Manenti and Ficetola 2013; Winandy and Denoël 2013). Prey cues were obtained by placing in a cylindrical tank (diameter: $30 \mathrm{~cm}$; water depth: $7 \mathrm{~cm}$ ) 97 starved mayfly larvae (40 larvae of the genus Baetis, 50 Ecdyonurus, two Ephemera and five Caenis) for $24 \mathrm{~h}$. We selected mayflies as they are abundant in surface streams inhabited by newts (Manenti et al. 2013a; Manenti and Bianchi 2014) and are different to the prey to which both urodele species were used to during their rearing period; the assemblage used reflects that of streams inhabited by the newts (Manenti et al. 2013a). The use of mayflies allowed us to avoid the effects of habituation (that could have arisen if we had used the Chironomus sp. or the Artemia salina with which newts and olms are normally fed), although this choice could potentially introduce a cue which the amphibians failed to recognise as coming from a prey species. We thus added to the test an additional cue, to control for responses toward unknown chemicals: lemon juice. Finally, we used water collected from the cave as a control. Each cue was freshly collected before every behavioural test session.

The experimental design consisted of multiple behavioural sessions in which the amphibians were individually exposed to the different cues (prey; predator; unknown; control) 
separately. For both newts and olms, behavioural sessions were performed after 7 days of starvation. The full test involved two replicates, so individuals were exposed twice to each different cue, for a total of eight trials. For newts, the test was performed both under light (600 lux) and under total darkness conditions; thus, each individual experienced 16 behavioural trials. Tests on olms were performed only under total darkness due to the sensitivity of this species to light and the likely stress induced. The order of cue presentation was completely randomized to minimise potential biases related to the sequence of cue exposure (Altmann 1974; Melotto et al. 2019).

Behavioural tests were performed in a $50 \times 40$-cm plastic arena (depth: $15 \mathrm{~cm}$ ) filled with water from the cave. The regular weekly feeding of animals was arranged to have all individuals starving for 7 days prior the tests. Before starting the test, Pyrenean newts were let acclimatise in the arena for $7 \mathrm{~min}$ and olms for $30 \mathrm{~min}$; as olms are more sensitive to stress, we decided to keep a longer time of acclimation (Uiblein et al. 1992). After the acclimation phase, $5 \mathrm{ml}$ of the selected cue treatment was injected in the centre of the arena and then the trial started. Trials lasted for $5 \mathrm{~min}$, during which the arena was video recorded using an H.264 DVR recording system connected to a Z210C IR camera. After trials, individuals were placed alone in a tank for $10 \mathrm{~min}$ recovering before the subsequent test. During this time, arenas were carefully washed three times with ground water to remove traces of cues from the previous test. After tests, individuals were fed as usual.

\section{Video analysis and behavioural parameters}

We analysed the videos using the software BORIS (Friard and Gamba 2016). BORIS is an event-logging software, which allows setting an ethogram coding behavioural displays of interest.

To describe activity and space use of both newts and olms, we considered three parameters describing their activity and space use. First we quantified total time spent in movement. Furthermore, we assessed the presence of a lateralised response by evaluating the time spent oriented in clockwise direction (exposing the right side of the body towards the centre of the arena) and the time spent oriented in anticlockwise direction (exposing the left side of the body towards the centre of the arena). In so doing, we considered individuals' orientation and quantified the exposure of each body side towards the centre of the arena. This allowed us to measure the occurrence of a lateralised response. During behavioural tests, urodeles tend to spend most of their time close to the tank borders, a behaviour interpreted as seeking what they perceive as the safest area of the experimental arenas. Moreover, during our tests, we injected cues in the centre of the arena, which can be considered the most exposed and potentially risky area (Manenti et al. 2013b). In our experimental arena, when individuals were in a clockwise orientation, they exposed their right side to central area, which according to lateralisation theory suggests them to be acting as predators (and also more prone to being preyed upon themselves), and conversely, individuals in anticlockwise orientation exposed their left side indicating a predator avoidance behaviour. While analysing the videos, we considered individuals to be oriented if they were with at least half of their bodies inside the border area ( $2 \mathrm{~cm}$ from the arena margin) with $<45^{\circ}$ of inclination towards the arena edge, and if their heads were not perpendicular to the border or along the bisector of the corner (Fig. 1a). When the head was perpendicular to the arena edge or along the bisector of the corner, we considered individuals to have no orientation (Fig. 1b). This produced three possible orientation conditions (clockwise; anticlockwise; no orientation), with the time spent in clockwise and anticlockwise orientation being two distinct not correlated parameters, and not merely the inverse of each other. A blind video analysis was performed by two operators: i.e. operators were not aware of the typology of trial they were going to analyse; this procedure allows us to limit biased interpretation (MacCoun and Perlmutter 2015).

\section{Statistical analysis}

We used the total time spent in movement, the time spent in clockwise orientation (exposing the right side deputed to prey search) and the time spent in anticlockwise orientation (exposing left side deputed to predator recognition) as dependent variables to build linear mixed models (LMMs): for both species, independent variables were the treatment (control, lemon, trout and prey), and for newts only, we also included the condition in which the test was performed (darkness vs. light) and the environment of origin (cave vs surface). Olms were tested in total darkness only and all shared the same origin. In models considering the time spent in clockwise orientation and the time spent in anticlockwise orientation as dependent variables, the initial orientation of individuals was added as a covariate. We tested all the possible pairwise interactions between independent variables; non-significant interactions were excluded from the final models. We included three random factors: the population of origin of the individuals (for newts only), the individual identity and the replicate. A preliminary test (GLM), found sex, snout-vent length and the operator that performed the video analysis to be not significant. Time spent in clockwise and anticlockwise orientation was $\log$ transformed to better fit a normal distribution. We first used control-treatment contrasts to compare the different experimental conditions against the controls (Field et al. 2015). Subsequently, we performed Tukey post hoc tests to assess differences between the different treatments for both newts and olms (Hothorn et al. 2008).We performed all the analyses 


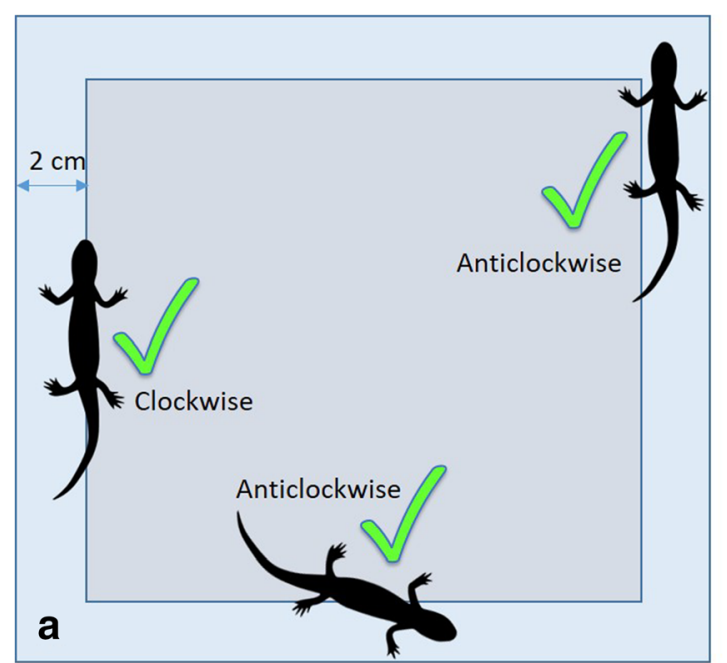

Fig. 1 Orientations considered (a) and not considered (b) in the assessment of lateralised responses of both Pyrenean newts and olms to the different cues tested during behavioural trials. We recorded the time of clockwise or anticlockwise orientation if the individuals were with at least

in R 3.4.1 (R Development Core Team 2017) environment using the packages lmerTest (Pinheiro and Bates 2000) and multcomp (Hothorn et al. 2008).

\section{Data availability}

The datasets generated and/or analysed during the current study are available from the corresponding author on reasonable request.

\section{Results}

\section{Behaviour of Pyrenean newts}

Overall, we performed 684 behavioural tests. Pyrenean newts from surface populations moved on average $( \pm$ SE) for 120.58 $\pm 2.17 \mathrm{~s}$, while those from caves moved for $107.54 \pm 2.97 \mathrm{~s}$. Newts from caves moved on average for $146.6 \pm 1.36 \mathrm{~s}$ when in darkness, while in light conditions, they moved on average for $143.72 \pm 2.01 \mathrm{~s}$; newts from streams moved for $148.7 \pm$ $0.53 \mathrm{~s}$ when in darkness, while in light, they moved for 148.09 $\pm 0.80 \mathrm{~s}$.

Both predator cues and light conditions significantly affected the total movement time of Pyrenean newts. Predator cues caused a significant reduction in the duration of movement, while light significantly increased movement (Table 1a; Fig. $2 \mathrm{a}, \mathrm{c})$. When predator cues occurred, newt movement was lower than control cues (Table 1a, $P<0.001$ ), but also than prey cues (Tukey's post hoc: $z=-6.46, P<0.001$ ) and unknown cues $(z=-5.99, P<0.001)$. The movement of newts was unaffected by either prey cues $\left(\right.$ Table $1 \mathrm{a} ; t_{577.7}=$ $-0.7, P=0.48)$, or by the unknown cues $\left(t_{578.4}=-0.25, P=\right.$

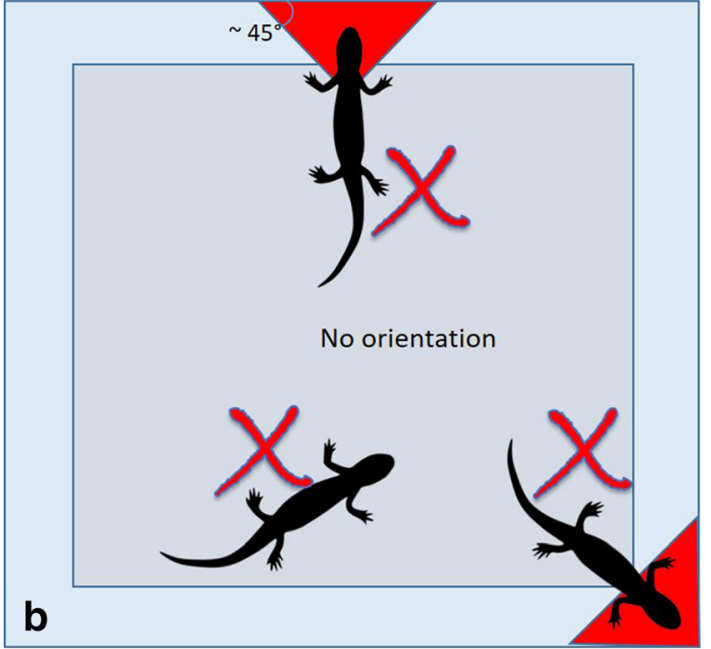

half of their bodies in the border area parallel to the border with no more than roughly $\sim 45^{\circ}$ inclination; the time spent in all the other possible positions was not considered

$0.79)$. Analyses did not show any effect of the environment of origin $\left(t_{5.8}=0.86, P=0.42\right)$ or any significant interaction between treatment and origin (all $P>0.05$ ); thus, both cave and surface Pyrenean newts responded similarly to predator cues.

Predator cues also affected the time spent by the newts in clockwise orientation. Predator cues caused a significant reduction of the time spent by newts in clockwise orientation (less exposure of the right side, linked to prey search; Fig. 3a); the reduction was even stronger under light conditions (Table 1b; Fig. 3c). The orientation of the animals at the beginning of the test affected the time spent in clockwise orientation (Table 1b). Moreover, with predator cues, newts spent significantly less time in clockwise orientation than with control conditions (Table 1b, $P<0.01$ ), prey $(\mathrm{z}=-3.75, P<$ $0.01)$ and unknown cues $(z=-4.17, P<0.01)$. Clockwise orientation was unaffected by prey cues or newts' origin. None of the factors affected the time spent in anticlockwise orientation, except for the effect of the orientation of the animals at the beginning of the experiment (Table 1c).

\section{Behaviour of olms}

Olms moved on average for $68.1 \pm 2.94 \mathrm{~s}$. Under control conditions, olms moved on average for $74.15 \pm 5.23 \mathrm{~s}$; with unknown scent, they moved for $77.59 \pm 6.57 \mathrm{~s}$, with prey cues $68.31 \pm 6.30 \mathrm{~s}$ and with predator cues $55.11 \pm 7.45 \mathrm{~s}$ (Fig. 4a). However, none of the treatments affected the total movement of olms, compared to the controls (all $P>0.05$; Table 2). Compared with unknown cues, olms moved less when predator cues occurred (Tukey's post hoc: $z=-3.08, P=0.01$ ). All the other comparisons among treatments were not significant (Supplementary Materials 1). For both orientations 
Table 1 Behavioural responses of Pyrenean newt $C$. asper to the treatments and test conditions depending on their origin

\begin{tabular}{|c|c|c|c|c|c|}
\hline & Estimate & SE & df & $t$ & $P$ \\
\hline \multicolumn{6}{|l|}{ (A) Total movement } \\
\hline Unknown cues (lemon) & -1.16 & 4.59 & 578.44 & -0.25 & 0.79 \\
\hline Prey cues & -3.25 & 4.60 & 577.70 & -0.70 & 0.48 \\
\hline Predator cues & -30.92 & 4.61 & 578.01 & -6.69 & $<0.001$ \\
\hline Surface origin & 13.81 & 16.01 & 5.84 & 0.86 & 0.42 \\
\hline Light condition & 21.83 & 3.25 & 578.08 & 6.70 & $<0.001$ \\
\hline \multicolumn{6}{|l|}{ (B) Clockwise time } \\
\hline Unknown cues (lemon) & 0.10 & 0.30 & 604.49 & 0.34 & 0.72 \\
\hline Prey cues & 0.22 & 0.30 & 604.51 & 0.76 & 0.44 \\
\hline Predator cues & -1.02 & 0.29 & 604.54 & -3.40 & $<0.001$ \\
\hline Surface origin & 0.32 & 0.24 & 4.60 & 1.31 & 0.23 \\
\hline Light condition & 0.04 & 0.30 & 604.93 & 0.16 & 0.86 \\
\hline Light : Predator & 1.36 & 0.42 & 605.03 & 3.18 & $<0.001$ \\
\hline Starting clockwise orientation & 1.68 & 0.17 & 609.17 & 9.55 & $<0.001$ \\
\hline \multicolumn{6}{|l|}{ (C) Anticlockwise time } \\
\hline Unknown cues (lemon) & 0.18 & 0.22 & 579.41 & 0.82 & 0.41 \\
\hline Prey cues & 0.39 & 0.22 & 578.09 & 1.78 & 0.07 \\
\hline Predator cues & -0.11 & 0.22 & 578.69 & -0.52 & 0.59 \\
\hline Surface origin & 0.21 & 0.21 & 5.21 & 0.98 & 0.36 \\
\hline Light condition & -0.09 & 0.15 & 582.00 & -0.62 & 0.53 \\
\hline Starting clockwise orientation & -1.67 & 0.20 & 587.65 & -8.14 & $<0.001$ \\
\hline Starting no orientation & -1.97 & 0.18 & 611.75 & -10.75 & $<0.001$ \\
\hline
\end{tabular}

The Table reports the control-treatment contrasts; significant effects are in bold. Only significant interactions are reported (clockwise and anticlockwise), we detected a significant effect of the initial orientation at the beginning of the test (Table 2). Considering the time spent in clockwise orientation (such as acting as a predator), prey cues differed to predator cues as olms showed a weak but significant tendency to spend more time in clockwise orientation with prey cues $(z=1.97, P=$ 0.05 ). We only detected a relationship close to significance when considering anticlockwise orientation: olms spent apparently less time in anticlockwise orientation when unknown cues occurred (Table 1; Fig. 4b).

\section{Discussion}

Our study revealed complex and heterogeneous responses of cave-dwelling urodeles to predator and prey cues. We hypothesised that shifting to a higher level in the trophic web might promote the loss of anti-predator responses (Predator detection decrease hypothesis). The limited responses in olms, which are the apex predators in groundwater, are in agreement with this hypothesis. However, this hypothesis is not confirmed for newts, as populations living in surface habitats (where fish are top predators) and populations occupying caves (safe environments) showed no difference in predator avoidance, and both maintained the capacity to express anti-predator responses when exposed to fish odours. This pattern can be explained by different processes. First of all, the isolation between surface and cave populations of the Pyrenean newt is likely very recent (Miaud and Guillaume 2005), even though a certain degree of physiological and behavioural differentiation between them already exists (Dreiss et al. 2009; Schlegel et al. 2009). Gene flow between cave and surface populations may have occurred until relatively recent times, allowing the maintenance of some behavioural traits typical of surface populations (Bachmann et al. 2020) even if populations from caves show lower genetic diversity compared with streams (Valbuena-Urena et al. 2018). Moreover, trout are likely still present in surface streams and newts could associate trout cues with the surface with its riskier environment. The retention of ability to identify physical or chemical cues typical of surface areas has been reported for some invertebrates inhabiting groundwaters that use these cues to avoid risky or suboptimal habitats. For instance, photophobic responses to light has been observed in cave amphipod crustaceans (Fišer et al. 2016) and avoidance of interface habitats rich in predators is reported for Niphargus crustaceans and planarians (Manenti and 
Fig. 2 Total time spent in movement by Pyrenean newts depending on the different cues used during tests (a), on the origin of the individuals (b) and on the light conditions at which we performed the tests $(\mathbf{c})$. Grey area identifies $95 \%$ confidence intervals; blue line indicates median

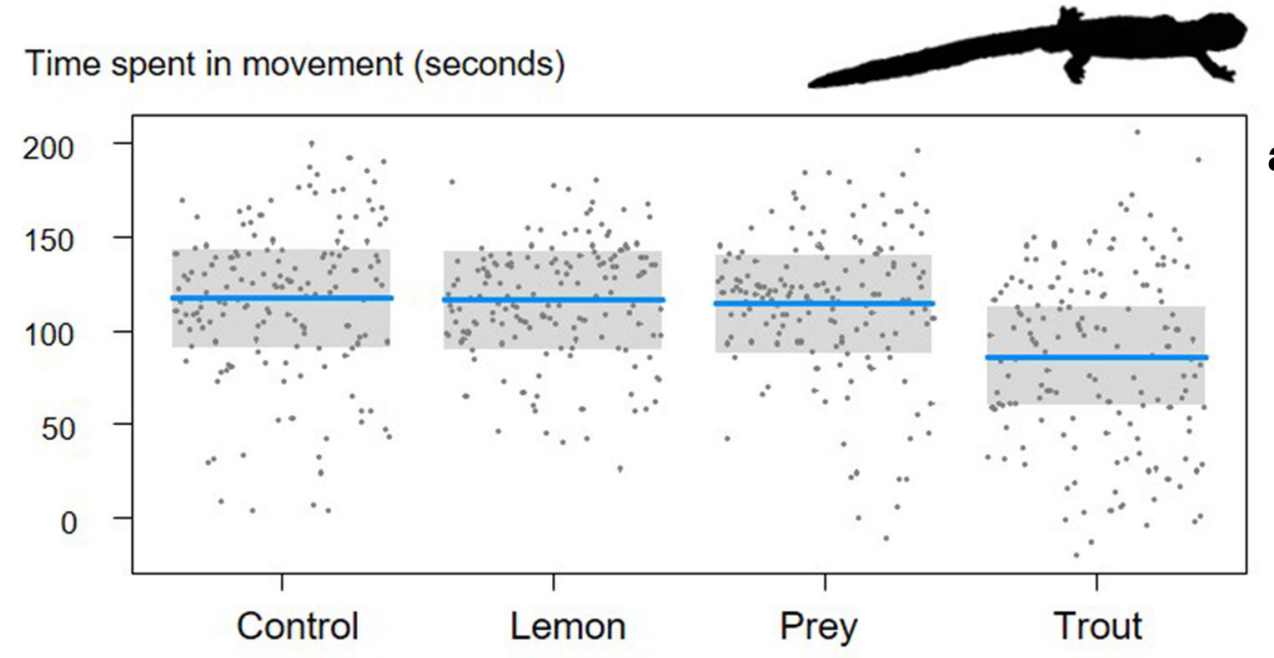

Time spent in movement (seconds)

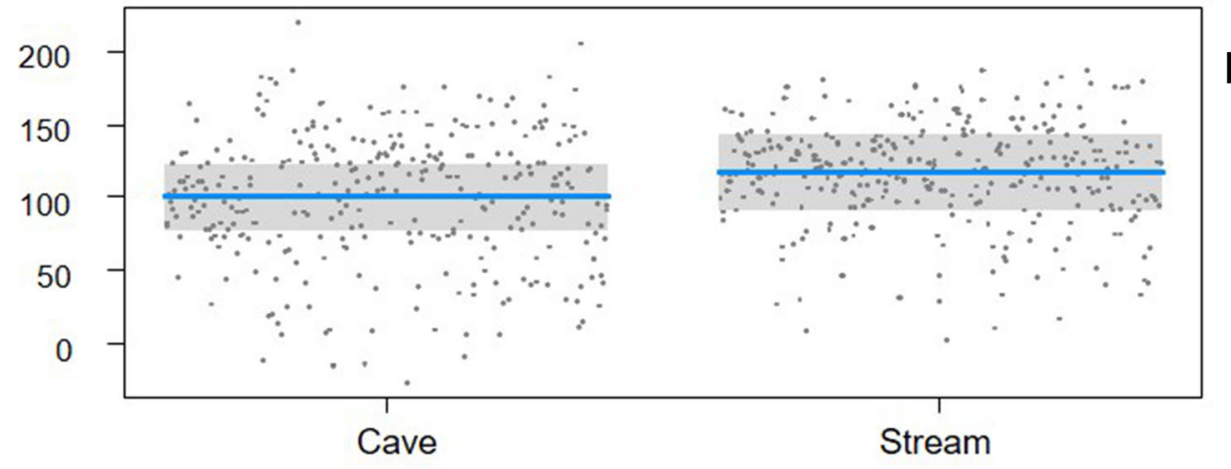

Time spent in movement (seconds)

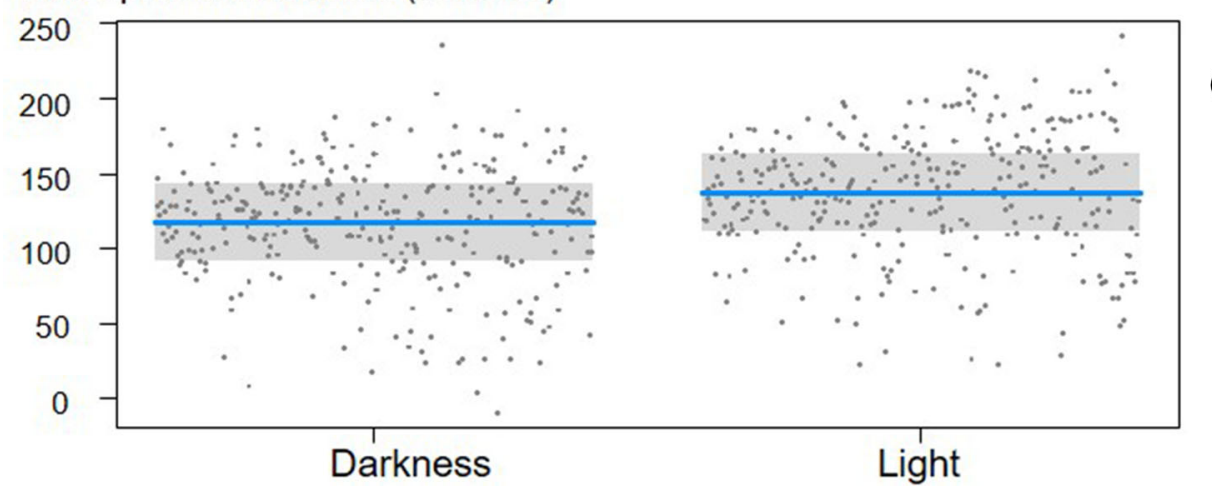

a
Pezzoli 2019); it is possible that the perception of predators' chemical cues by the cave newts acts in a similar way.

Conversely, olms likely colonised caves through multiple and spatially different events that are supposed to have occurred from 8 to $20 \mathrm{Myr}$ ago (Trontelj et al. 2007). All the olm lineages show strong adaptations to subterranean life, including reduction of eyes and depigmentation. Even though there are occasional reports of individuals outside groundwaters and some populations live in contact to springs and show eyed and pigmented morphotypes (Ivanovic et al. 2013), no stable surface populations exist, and isolation between populations living in different drainage catchments is strong (Voros et al. 2019). The only responses we detected was a reduction in total movement between predator and lemon cues, and a 
Fig. 3 Time spent moving in clockwise orientation (thus exposing the right body side involved in prey detection) by Pyrenean newts depending on the different cues used during tests (a), on the origin of the individuals (b) and on the light conditions at which we performed the tests (c). Grey area identifies 95\% confidence intervals; blue line indicates median

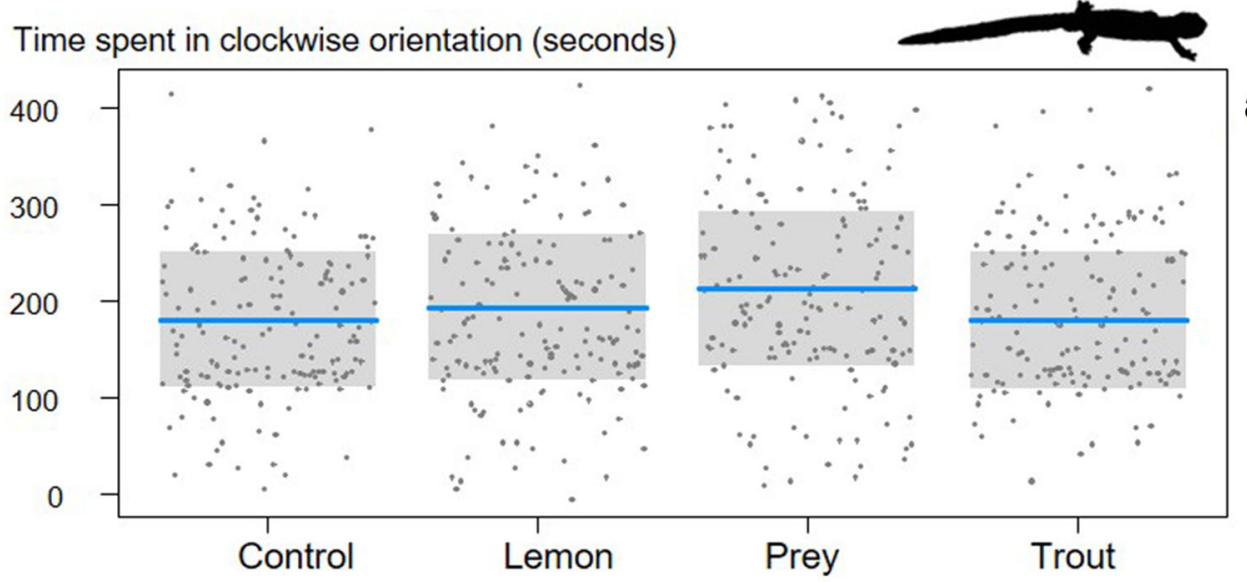

a

Time spent in clockwise orientation (seconds)

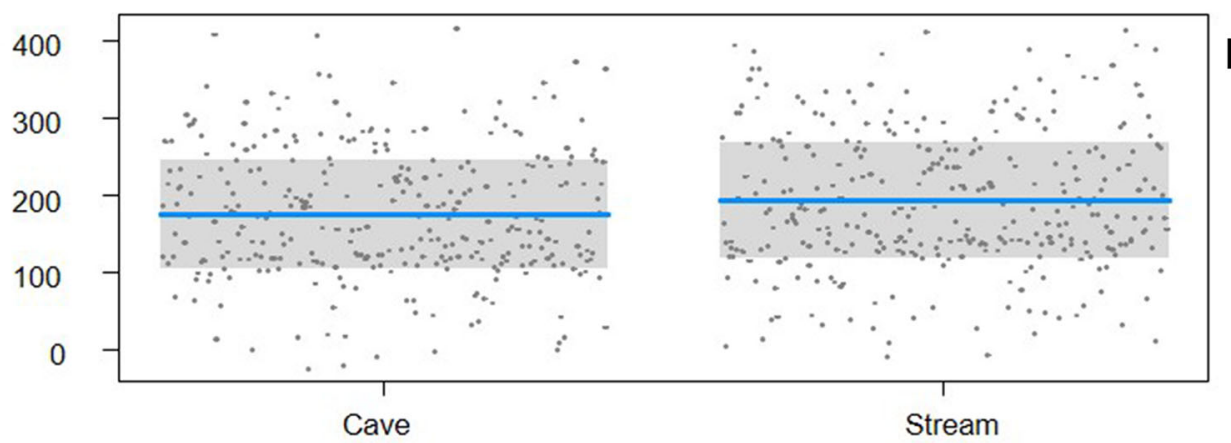

Time spent in clockwise orientation (seconds)

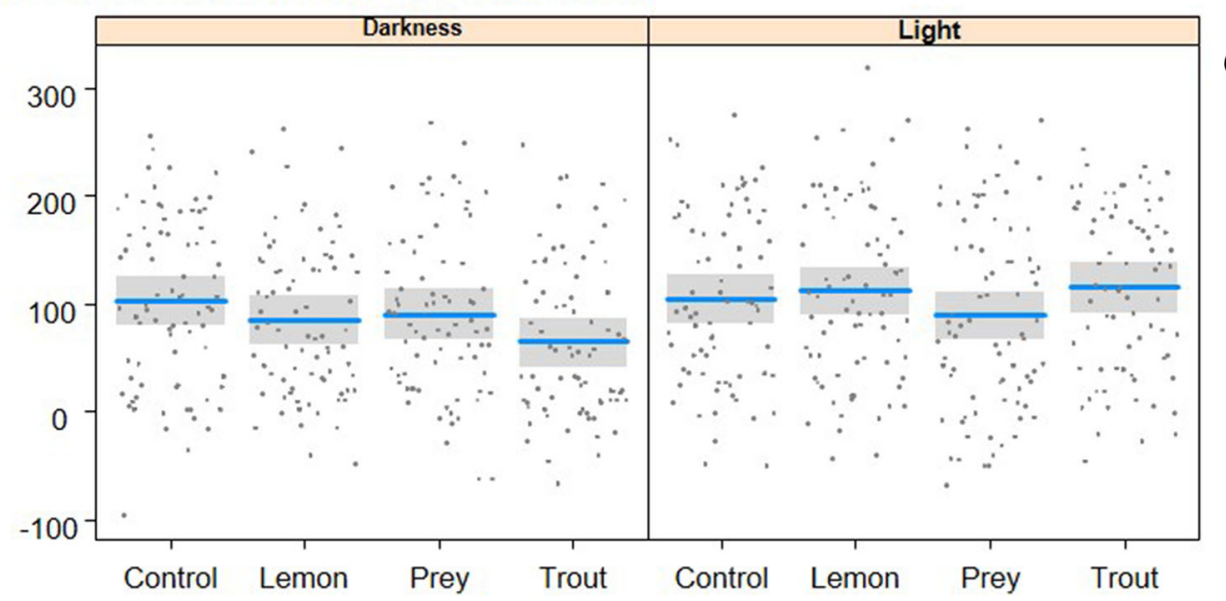

weak increase of the time in clockwise orientation with prey cues, compared with predator cues, in agreement with lateralisation patterns already described in other urodeles. Our results suggest that during the process of adaptation to subterranean environments, where they play the role of apex predators, olms decreased the ability to recognise fish as predators. Maintaining unnecessary behaviours is costly for species, so when olms adapted to a predator-free environment, the ability to detect predators and the related behavioural traits were lost through evolutionary processes (Burns et al. 2011).

On the other hand, we found no support for the prey detection ability increase hypothesis. Both Pyrenean newts and olms spent more time in clockwise orientation (thus acting as predators) with prey cues than with trout cues, and for olms, this relationship was close to the significance threshold. The prey used, from common Ephemeroptera genera, is typical of 
Table 2 Behavioural responses of Proteus anguinus to the treatments

\begin{tabular}{lccccc}
\hline & Estimate & SE & df & $t$ & $P$ \\
\hline (A) Total movement & & & & & \\
$\quad$ Unknown cues (lemon) & 0.19 & 0.10 & 49.46 & 1.78 & 0.08 \\
Prey cues & 0.03 & 0.10 & 49.00 & 0.01 & 0.98 \\
Predator cues & -0.11 & 0.10 & 49.01 & -1.23 & 0.22 \\
(B) Anticlockwise time & & & & & \\
Unknown cues (lemon) & -1.23 & 0.62 & 54.00 & -1.98 & 0.05 \\
Prey cues & -0.63 & 0.58 & 54.00 & -1.08 & 0.28 \\
Predator cues & -0.88 & 0.58 & 54.00 & -1.52 & 0.13 \\
Starting no orientation & -0.62 & 0.72 & 54.00 & -0.86 & 0.39 \\
Starting clockwise orientation & -2.35 & 0.45 & 54.00 & -5.19 & $<\mathbf{0 . 0 0 1}$ \\
(C) Clockwise time & & & & & \\
Unknown cues (lemon) & 0.67 & 0.86 & 49.82 & 0.78 & 0.43 \\
Prey cues & 1.28 & 0.80 & 47.13 & 159 & 0.11 \\
Predator cues & -0.69 & 0.79 & 48.07 & -0.87 & 0.38 \\
Starting no orientation & 0.96 & 1.01 & 51.34 & 0.95 & 0.34 \\
Starting clockwise orientation & 2.99 & 0.62 & 53.03 & 4.78 & $<\mathbf{0 . 0 0 1}$ \\
\hline
\end{tabular}

The Table reports the control-treatment contrasts; significant effects are in bold the surface freshwaters inhabited by $C$. asper (Manenti et al. 2013a), but rare in caves, into which they would only enter accidentally (Martynov and Vargovitsh 2015). We had chosen to use the cues of these animals instead of those of the prey with which the animals are reared in order to test for innate response. The results obtained clearly show that anti-predator responses, at least in Pyrenean newts, are stronger that those related to potential prey recognition.

Considering olms, the methods followed are similar to those applied in other behavioural studies as was the number of individuals that were available for the experiment. Considering predatory behaviour, the olm is able to detect their prey's chemical cues over a longer distance than Pyrenean newt (Uiblein et al. 1992); olms generally explore the substrate actively searching for prey especially in the sediment (Schlegel et al. 2009). Both mechano-, chemo- and eventually electro-perception are used to detect prey (Schlegel 1997).

The only weak and not significant effect that we recorded was a tendency to expose less the left side deputed to predator detection when unknown cues occurred; moreover, olm did not show significant neophobic responses to these cues. In several subterranean environments, there is an important input of allochthonous organic matter originating from the surface (Manenti et al. 2013c; Lunghi et al. 2017), part of which can be unknown for cave species that can be attracted by curiosity/ exploration. Absence of neophobic responses towards unknown cues has been observed also as a side effect in plastic and quick-breeding fish reared in safe conditions (Brown et al. 2013); however, the lack of predation risk is the natural condition of olms and their rearing conditions respect those of natural groundwaters. In our study, we could consider a relatively low number of olms, due to logistical limitations. We used a number of individuals comparable with previous evolutionary zoological studies performed on both Pyrenean newts and olms (Uiblein et al. 1992; Guillaume 2000; Hervant et al. 2001), and we performed an extensive number of tests to achieve reliable results. Even if we cannot exclude that increasing the number of olms or considering individuals deriving from different populations could evidence potential responses, we believe that the results obtained provide useful insights to extend such kind of behavioural experiment to other cave-dwelling taxa with more abundant populations. While cave-dwelling amphibians have a long history of zoological studies, but are often numerically rare, cave-dwelling invertebrates are much less studied and known, but show larger subterranean populations (Manenti et al. 2020) and can provide a tractable system for further researches.

Our results also provide insights on the importance of considering lateralisation in the behaviour of urodeles (Izvekov et al. 2018). A common basic pattern of lateralisation is likely to occur in all the vertebrates (Robins 2006). The investigation of lateralisation is important for behavioural studies on many taxa, including humans (Rogers 2010), and can allow us to increase our ability in detecting possible responses and patterns that may go unnoticed with classical parametrisations. Integrating lateralisation in the behavioural parameters allowed us to better understand the effect of predator cues. However, our results underline also that caution must be used in the assessment of lateralisation during experimental approaches. In all analyses, the initial orientation of the individuals played a significant effect on the total time spent moving in a certain orientation. Especially for less reactive and more slow-moving animals like olms (Hervant et al. 2000; Balazs 
Time spent in movement (seconds)
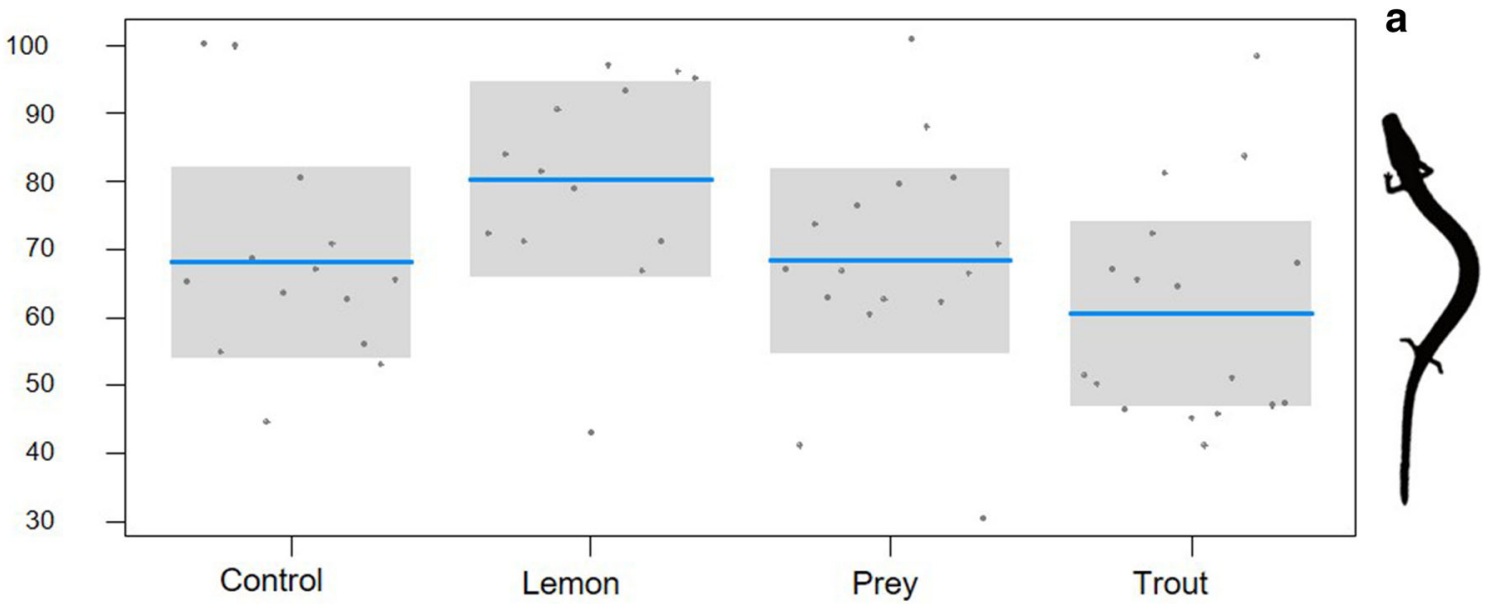

Time spent in anticlockwise orientation (seconds)

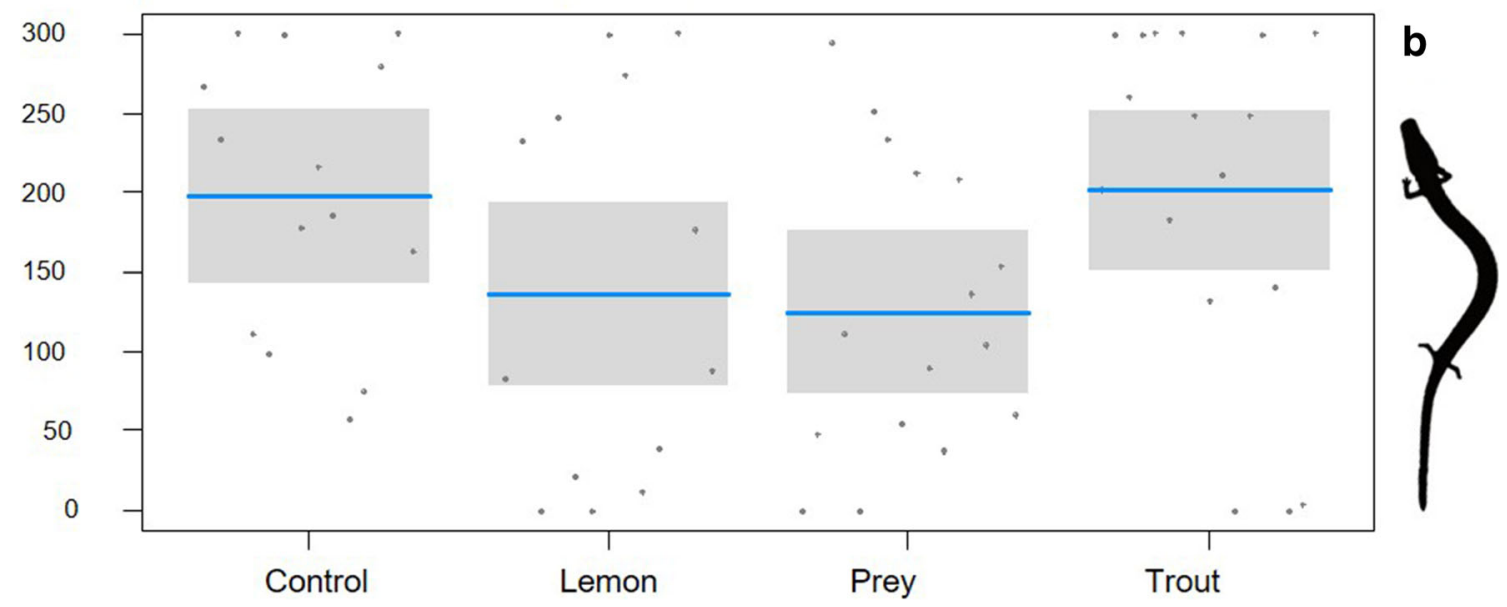

Fig. 4 Total time spent by olms moving (a) and in anticlockwise orientation (thus exposing the left body side involved in predator recognition) (b) depending on the different cues used during tests. Grey area identifies $95 \%$ confidence intervals; blue line indicates median

et al. 2015), this could represent an aspect to be attentively considered during experiments.

Finally, newts moved more in light conditions than in darkness conditions. This result is in contrast with a similar experiment performed on salamander larvae, which have higher activity and improved foraging performance in darkness (Manenti and Ficetola 2013). It may also appear to contrast with the findings of field surveys who found Pyrenean newts to be more active at night (Manenti et al. 2013a; Miró and Ventura 2020). Pyrenean newts mainly use visual cues to catch prey (Uiblein et al. 1992, 1995); we can interpret their increased activity in light condition as a preference to actively hunt using visual cues when they have this possibility. Furthermore, the absolute darkness of laboratory conditions is very different to the situation in a natural setting where there will be moonlight and other sources of illumination, albeit at quite low levels.

For many years, organisms that are strongly adapted to subterranean environments have been key models for understanding evolutionary mechanisms (Romero 2011; Culver and Pipan 2014; Manenti et al. 2018). Taxa that are usually epigean but show some periods of subterranean activity, or have some populations colonising subterranean habitats, can be particularly important to understand the complex processes occurring during adaptation to these extreme environments (Manenti et al. 2011; Lunghi et al. 2017). The broad implication of our results is that predator recognition is maintained across populations of the same species occupying both meso- and apex predator levels, but this occurs when differentiation is recent, while the ability of detecting surface predators is lost in species with longer history of adaptation to subterranean environments.

Acknowledgements We are grateful to David O'Brien and Catherine O'Brien for the revision of an early version of the manuscript. We thank the Subterranean Laboratory of Moulis (Ariège, France) for the exceptional possibility to perform the test on the reared Pyrenean newts and olms in the historical facility. We thank P. Meroni and D. Ramella for performing video analyses. The study was supported by the subterranean 
biological laboratory "Laboratorio di Biologia Sotterranea "Enrico Pezzoli" of the Monte Barro Regional Park. We thank also two anonymous reviewers for useful suggestions on a previous version of the manuscript.

Funding Open access funding provided by Università degli Studi di Milano within the CRUI-CARE Agreement. EL is supported by the Chinese Academy of Sciences President's International Fellowship Initiative for postdoctoral researchers.

\section{Compliance with ethical standards}

Conflict of interest The authors declare that they have no conflict of interest.

Ethical approval The authors declare that the study complies with the international animal care guidelines, and under all required French permits accredited to the Subterranean Laboratory of Moulis/CNRS SETE Moulis by the "Ministère de l'Education Nationale, de l'Enseignement Supérieur et de la Recherche". The involvement of the animals in behavioural experiments was approved by the French ethics committee "Comité d'Éthique en Experimentation Animale". In particular this study was in agreement with permits no. 2007, 52/2007b, 1935/2007, 2007-111342 relating to an authorisation of capture, marking, transport, detention, use, release of protected amphibian species, no. 09-219 allowing the Amphibian rearing capacity, no. 0108 addressing a breeding agreement. The animal experimentation ethical accreditation $\mathrm{n}^{\circ} \mathrm{A} 09-1$ allowed us to use Pyrenean newts and olms for the behavioural tests performed during the study that followed all the national ethical committee requirements.

Open Access This article is licensed under a Creative Commons Attribution 4.0 International License, which permits use, sharing, adaptation, distribution and reproduction in any medium or format, as long as you give appropriate credit to the original author(s) and the source, provide a link to the Creative Commons licence, and indicate if changes were made. The images or other third party material in this article are included in the article's Creative Commons licence, unless indicated otherwise in a credit line to the material. If material is not included in the article's Creative Commons licence and your intended use is not permitted by statutory regulation or exceeds the permitted use, you will need to obtain permission directly from the copyright holder. To view a copy of this licence, visit http://creativecommons.org/licenses/by/4.0/.

\section{References}

Altmann J (1974) Observational study of behavior: sampling methods. Behaviour 49:227-267

Arim M, Bozinovic F, Marquet PA (2007) On the relationship between trophic position, body mass and temperature: reformulating the energy limitation hypothesis. Oikos 116:1524-1530. https://doi.org/ 10.1111/j.2007.0030-1299.15768.x

Bachmann JC, Jansen van Rensburg A, Cortazar-Chinarro M, Laurila A, Van Buskirk J (2020) Gene flow limits adaptation along steep environmental gradients. Am Nat:E67-E86. https://doi.org/10.1086/707209

Balazs G, Lewarne B, Herczeg G (2015) In situ underwater tagging of aquatic organisms: a test using the cave-dwelling olm, Proteus anguinus. Ann Zool Fenn 52:160-166. https://doi.org/10.5735/ 086.052.0303

Balazs G, Lewarne B, Herczeg G (2020) Extreme site fidelity of the olm (Proteus anguinus) revealed by a long-term capture-mark-recapture study. J Zool 311:99-105. https://doi.org/10.1111/jzo.12760
Barzaghi B, Ficetola GF, Pennati R, Manenti R (2017) Biphasic predators provide biomass subsidies in small freshwater habitats: A case study of spring and cave pools. Freshw Biol 62:1637-1644. https://doi. org/10.1111/fwb. 12975

Behrmann-Godel J, Nolte AW, Kreiselmaier J, Berka R, Freyhof J (2017) The first European cavefish. Curr Biol 27:R257-R258

Bleicher SS (2017) The landscape of fear conceptual framework: definition and review of current applications and misuses Peerj 5:e3772. https://doi.org/10.7717/peerj.3772

Bonati B, Csermely D, Lopez P, Martin J (2010) Lateralization in the escape behaviour of the common wall lizard (Podarcis muralis). Behav Brain Res 207:1-6. https://doi.org/10.1016/j.bbr.2009.09. 002

Bonati B, Csermely D, Sovrano VA (2013) Advantages in exploring a new environment with the left eye in lizards. Behav Process 97:80 83. https://doi.org/10.1016/j.beproc.2013.04.002

Bradley JG, Eason PK (2018) Predation risk and microhabitat selection by cave salamanders, Eurycea lucifuga (Rafinesque, 1822). Behaviour 155:841-859. https://doi.org/10.1163/1568539x00003505

Braga J, Pollock LJ, Barros C, Galiana N, Montoya JM, Gravel D, Maiorano L, Montemaggiori A, Ficetola GF, Dray S, Thuiller W (2019) Spatial analyses of multi-trophic terrestrial vertebrate assemblages in Europe. Global Ecol Biogeogr 28:1636-1648. https://doi. org/10.1111/geb.12981

Brown GE, Godin J-GJ (1999) Who dares, learns: chemical inspection behaviour and acquired predator recognition in a characin fish. Anim Behav 57:475-481. https://doi.org/10.1006/anbe.1998.1017

Brown GE, Ferrari MCO, Elvidge CK, Ramnarine I, Chivers DP (2013) Phenotypically plastic neophobia: a response to variable predation risk. Proc R Soc B 280:20122712. https://doi.org/10.1098/Rspb. 2012.2712

Bulog B (1994) Two decades of functional-morphological studies of Proteus anguinus (Amphibia, Caudata). Acta Carsol 19:247-263

Burns JG, Foucaud J, Mery F (2011) Costs of memory: lessons from 'mini' brains. Proc R Soc Lond B 278:923-929. https://doi.org/10. 1098/rspb.2010.2488

Carranza S, Amat F (2005) Taxonomy, biogeography and evolution of Euproctus (Amphibia: Salamandridae), with the resurrection of the genus Calotriton and the description of a new endemic species from the Iberian Peninsula. Zool J Linn Soc-Lond 145:555-582. https:// doi.org/10.1111/j.1096-3642.2005.00197.x

Chin JSR, Gassant CE, Amaral PM, Lloyd E, Stahl BA, Jaggard JB, Keene AC, Duboue ER (2018) Convergence on reduced stress behavior in the Mexican blind cavefish. Dev Biol 441:319-327. https://doi.org/10.1016/j.ydbio.2018.05.009

Culver DC, Pipan T (2014) Shallow Subterranean Habitats. Oxford University Press, Oxford

Culver DC, Pipan T (2019) The biology of caves and other subterranean habitats, 2nd edn. Oxford University Press, New York

Development Core Team R (2017) R: a language and environment for statistical computing. R Foundation for Statistical Computing, Vienna http://www.R-project.org

Diquelou MC, Griffin AS (2019) It's a trap! Invasive common mynas learn socially about control-related cues. Behav Ecol 30:1314 1323. https://doi.org/10.1093/beheco/arz079

Donadio E, Buskirk SW (2016) Linking predation risk, ungulate antipredator responses, and patterns of vegetation in the high Andes. J Mammal 97:966-977. https://doi.org/10.1093/jmammal/gyw020

Dreiss AN, Guillaume O, Clobert J (2009) Diverging cave- and riverdwelling newts exert the same mate preference in their native light conditions. Ethology 115:1036-1045

Eklov P, Svanback R (2006) Predation risk influences adaptive morphological variation in fish populations. Am Nat 167:440-452. https:// doi.org/10.1086/499544 
Fernandes VFL, Macaspac C, Lu L, Yoshizawa M (2018) Evolution of the developmental plasticity and a coupling between left mechanosensory neuromasts and an adaptive foraging behavior. Dev Biol 441:262-271. https://doi.org/10.1016/j.ydbio.2018.05. 012

Ferrari MCO, Chivers DP (2009) Sophisticated early life lessons: threatsensitive generalization of predator recognition by embryonic amphibians. Behav Ecol 20:1295-1298. https://doi.org/10.1093/ beheco/arp135

Ferrari MCO, Messier F, Chivers DP, Messier O (2008) Can prey exhibit threat-sensitive generalization of predator recognition? Extending the Predator Recognition Continuum Hypothesis. Proc R Soc Lond B 275:1811-1816. https://doi.org/10.1098/rspb.2008.0305

Field A, Miles J, Field Z (2015) Discovering statistics using R. SAGE Publications, London

Fišer Z, Novak L, Lustrik R, Fiser C (2016) Light triggers habitat choice of eyeless subterranean but not of eyed surface amphipods. Sci Nat 103:7. https://doi.org/10.1007/s00114-015-1329-9

Friard O, Gamba M (2016) BORIS: a free, versatile open-source eventlogging software for video/audio coding and live observations. Methods Ecol Evol 7:1325-1330. https://doi.org/10.1111/2041210x.12584

Guillaume O (2000) Role of chemical communication and behavioural interactions among conspecifics in the choice of shelters by the cave-dwelling salamander Proteus anguinus (Caudata, Proteidae). Can J Zool 78:167-173

Haddaway NR, Vieille D, Mortimer RJG, Christmas M, Dunn AM (2014) Aquatic macroinvertebrate responses to native and nonnative predators. Knowl Managt Aquatic Ecosyst 415:10. https:// doi.org/10.1051/kmae $/ 2014036$

Haidir IA, Macdonald DW, Linkie M (2018) Assessing the spatiotemporal interactions of mesopredators in Sumatra's tropical rainforest. PLoS ONE 13:e0202876. https://doi.org/10.1371/journal.pone. 0202876

Hervant F, Mathieu J, Durand JP (2000) Metabolism and circadian rhythms of the European blind cave salamander Proteus anguinus and a facultative cave dweller, the Pyrenean newt (Euproctus asper). Can J Zool 78:1427-1432

Hervant F, Mathieu J, Durand J (2001) Behavioural, physiological and metabolic responses to long-term starvation and refeeding in a blind cave-dwelling (Proteus anguinus) and a surface-dwelling (Euproctus asper) salamander. J Exp Biol 204:269-281

Hopkins GR, Gall BG, Brodie ED (2011) Ontogenetic shift in efficacy of antipredator mechanisms in a top aquatic predator, Anax junius (Odonata: Aeshnidae). Ethology 117:1093-1100. https://doi.org/ 10.1111/j.1439-0310.2011.01963.x

Hothorn T, Bretz F, Westfall P (2008) Simultaneous inference in general parametric models. Biom J 50:346-363. https://doi.org/10.1002/ bimj.200810425

Hughes NK, Price CJ, Banks PB (2010) Predators are attracted to the olfactory signals of prey. PLoS ONE 5:e13114. https://doi.org/10. 1371/journal.pone.0013114

Ivanovic A, Aljancic G, Arntzen JW (2013) Skull shape differentiation of black and white olms (Proteus anguinus anguinus and Proteus a. parkelj): an exploratory analysis with micro-CT scanning. Contrib Zool 82:107-114. https://doi.org/10.1163/18759866-08202004

Izvekov EI, Pavlova VV, Ognevaja EM, Nepomnyashchikh VA, Malashichev YB (2018) Pattern of lateralized behaviors in a caudate amphibian, Ambystoma mexicanum. Russ J Herpetol 25:31-42

Jimenez-Valverde A, Sendra A, Garay P, Reboleira ASPS (2017) Energy and speleogenesis: Key determinants of terrestrial species richness in caves. Ecol Evol 7:10207-10215. https://doi.org/10.1002/ece3. 3558

Juberthie C (1991) Service d'élevage des Protées Laboratoire souterrain du C.N.R.S. Mém Biospéol 18:315-318
Kishida O, Trussell GC, Nishimura K, Ohgushi T (2009) Inducible defenses in prey intensify predator cannibalism. Ecology 90:3150 3158. https://doi.org/10.1890/08-2158.1

Lima SL, Dill LM (1990) Behavioral decisions made under the risk of predation - a review and prospectus. Can J Zool 68:619-640

Lucati F, Poignet M, Miro A et al (2020) Multiple glacial refugia and contemporary dispersal shape the genetic structure of an endemic amphibian from the Pyrenees. Mol Ecol 29:2904-2921. https://doi. org $/ 10.1111 /$ mec. 15521

Lunghi E, Manenti R, Ficetola GF (2017) Cave features, seasonality and subterranean distribution of non-obligate cave dwellers. Peerj 5: e3169. https://doi.org/10.7717/peerj.3169

MacCoun R, Perlmutter S (2015) Hide results to seek the truth. Nature 526:187-189. https://doi.org/10.1038/526187a

Manenti R, Bianchi B (2014) Distribution of the Triclad Polycelis felina (Planariidae) in Aezkoa Mountains: effect of stream biotic features. Acta Zool Bulg 66:271-275

Manenti R, Ficetola GF (2013) Salamanders breeding in subterranean habitats: local adaptations or behavioural plasticity? J Zool 289: 182-188. https://doi.org/10.1111/j.1469-7998.2012.00976.x

Manenti R, Pezzoli E (2019) Think of what lies below, not only of what is visible above, or: a comprehensive zoological study of invertebrate communities of spring habitats. Eur Zool J 86:272-279. https://doi. org/10.1080/24750263.2019.1634769

Manenti R, Ficetola GF, De Bernardi F (2009) Water, stream morphology and landscape: complex habitat determinants for the fire salamander Salamandra salamandra. Amphibia-Reptilia 30:7-15. https://doi. org/10.1163/156853809787392766

Manenti R, Ficetola GF, Marieni A, De Bernardi F (2011) Caves as breeding sites for Salamandra salamandra: habitat selection, larval development and conservation issues. North-West J Zool 7:304-309

Manenti R, De Bernardi F, Ficetola GF (2013a) Pastures vs forests: do traditional pastoral activities negatively affect biodiversity? The case of amphibians communities. North-West J Zool 9:284-292

Manenti R, Denoël M, Ficetola GF (2013b) Foraging plasticity favours adaptation to new habitats in fire salamanders. Anim Behav 86:375382. https://doi.org/10.1016/j.anbehav.2013.05.028

Manenti R, Siesa ME, Ficetola GF (2013c) Odonata occurence in caves: active or accidentals? A new case study. J Cave Karst Stud 75:205209. https://doi.org/10.4311/2012LSC0281

Manenti R, Pennati R, Ficetola GF (2015) Role of density and resource competition in determining aggressive behaviour in salamanders. $\mathrm{J}$ Zool 296:270-277

Manenti R, Lunghi E, Ficetola GF (2017) Cave exploitation by an usual epigean species: a review on the current knowledge on fire salamander breeding in cave. Biogeographia 32:31-46

Manenti R, Barzaghi B, Lana E, Stocchino GA, Manconi R, Lunghi E (2018) The stenoendemic cave-dwelling planarians (Platyhelminthes, Tricladida) of the Italian Alps and Apennines: Conservation issues. J Nat Conserv 45:90-97. https://doi.org/10. 1016/j.jnc.2018.08.001

Manenti R, Lunghi E, Barzaghi B, Melotto A, Falaschi M, Ficetola GF (2020) Do salamanders limit the abundance of groundwater invertebrates in subterranean habitats? Diversity 12:161

Martynov AV, Vargovitsh RS (2015) Paraleptophlebia werneri Ulmer, 1919 (Ephemeroptera, Leptophlebiidae) from the West caucasian caves with notes on mayflies potential for cave colonisation. Entomol News 125:239-244. https://doi.org/10.3157/021.125.0403

Meager JJ, Batty RS (2007) Effects of turbidity on the spontaneous and prey-searching activity of juvenile Atlantic cod (Gadus morhua). Phil Trans R Soc B 362:2123-2130. https://doi.org/10.1098/rstb. 2007.2104

Melotto A, Ficetola GF, Manenti R (2019) Safe as a cave? Intraspecific aggressiveness rises in predator-devoid and resource-depleted environments. Behav Ecol Sociobiol 73:68 
Miaud C, Guillaume O (2005) Variation in age, body size and growth among surface and cave-dwelling populations of the Pyrenean newt, Euproctus asper (Amphibia; Urodela). Herpetologica 61:241-249

Miró A, Ventura M (2020) Introduced fish in Pyrenean high mountain lakes: impact on amphibians and other organisms, and conservation implications. Limnetica 39:283-297

Peckarsky BL, Abrams PA, Bolnick DI, Dill LM, Grabowski JH, Luttbeg B, Orrock JL, Peacor SD, Preisser EL, Schmitz OJ, Trussell GC (2008) Revisiting the classics: Considering nonconsumptive effects in textbook examples of predator-prey interactions. Ecology 89: 2416-2425. https://doi.org/10.1890/07-1131.1

Pinheiro JC, Bates DM (2000) Linear mixed-effects models: basic concepts and examples. In: Mixed-effects models in S and S-Plus. Springer, New York, pp 3-56

Policht R, Hart V, Goncharov D, Surovy P, Hanzal V, Cerveny J, Burda H (2019) Vocal recognition of a nest-predator in black grouse. Peerj 7:e6533. https://doi.org/10.7717/peerj.6533

Ritchie EG, Johnson CN (2009) Predator interactions, mesopredator release and biodiversity conservation. Ecol Lett 12:982-998. https:// doi.org/10.1111/j.1461-0248.2009.01347.x

Robins A (2006) Lateralized visual processing in anurans: New vistas through ancient eyes. In: Malashichev YB, Deckel AW (eds) Behavioural and Morphological Asymmetries in Vertebrates. Landes Bioscience, Georgetown, pp 86-106

Rogers LJ (2010) Relevance of brain and behavioural lateralization to animal welfare. Appl Anim Behav Sci 127:1-11. https://doi.org/ 10.1016/j.applanim.2010.06.008

Romero A (2009) Cave biology. Cambridge University Press, New York. https://doi.org/10.1017/CBO9780511596841

Romero A (2011) The evolution of cave life. Am Sci 99:144-151. https:// doi.org/10.1511/2011.89.144

Roos S, Smart J, Gibbons DW, Wilson JD (2018) A review of predation as a limiting factor for bird populations in mesopredator-rich landscapes: a case study of the UK. Biol Rev 93:1915-1937

Salvidio S, Palumbi G, Romano A, Costa A (2017) Safe caves and dangerous forests? Predation risk may contribute to salamander colonization of subterranean habitats. Sci Nat 104:20. https://doi.org/10. 1007/s00114-017-1443-y

Schlegel PA (1997) Behavioral sensitivity of the European blind cave salamander, Proteus anguinus, and a Pyrenean newt, Euproctus asper, to electrical fields in water. Brain Behav Evolut 49:121-131
Schlegel PA, Steinfartz S, Bulog B (2009) Non-visual sensory physiology and magnetic orientation in the Blind Cave Salamander, Proteus anguinus (and some other cave-dwelling urodele species). Review and new results on light-sensitivity and non-visual orientation in subterranean urodeles (Amphibia). Anim Biol 59:351-384

Schnell AK, Hanlon RT, Benkada A, Jozet-Alves C (2016) Lateralization of eye use in cuttlefish: opposite direction for anti-predatory and predatory behaviors. Front Physiol 7:620

Start D (2018) Ontogeny and consistent individual differences mediate trophic interactions. Am Nat 192:301-310. https://doi.org/10.1086/ 698693

Trontelj P, Goricki S, Polak S, Verovnik R, Zaksek V, Sket B (2007) Age estimates for some subterranean taxa and lineages in the Dinaric Karst. Acta Carsol 36:183-189

Uiblein F, Durand JP, Juberthie C, Parzefall J (1992) Predation in caves the effects of prey immobility and darkness on the foraging behavior of two salamanders, Euproctus asper and Proteus anguinus. Behav Process 28:33-40. https://doi.org/10.1016/0376-6357(92)90046-G

Uiblein F, Engelke S, Parzefall J (1995) Trade-off between visual detectability and nutrient content in the patch choice of the Pyrenean salamander Euproctus asper. Ethology 101:39-45

Urban MC (2007) Risky prey behavior evolves in risky habitats. P Natl Acad Sci USA 104:14377-14382. https://doi.org/10.1073/pnas. 0704645104

Valbuena-Urena E, Oromi N, Soler-Membrives A et al (2018) Jailed in the mountains: genetic diversity and structure of an endemic newt species across the Pyrenees. PLoS ONE 13:e0200214. https://doi. org/10.1371/journal.pone.0200214

Vandel A, Bouillon M (1954) Le protée et son intérêt biologique. Ann Spéléol 14:111-127

Voros J, Ursenbacher S, Jelic D (2019) Population genetic analyses using 10 new polymorphic microsatellite loci confirms genetic subdivision within the Olm, Proteus anguinus. J Hered 110:211-218. https://doi.org/10.1093/jhered/esy067

Winandy L, Denoël M (2013) Cues from introduced fish alter shelter use and feeding behaviour in adult alpine newts. Ethology 119:121129. https://doi.org/10.1111/eth.12043

Publisher's note Springer Nature remains neutral with regard to jurisdictional claims in published maps and institutional affiliations. 